\title{
Influence of the Gastrointestinal Iodide Cycle on the Early Distribution of Radioactive Iodide in Man *
}

\author{
Marguerite T. Hays † and David H. Solomon \\ (From the Department of Medicine, University of California, Los Angeles, Calif.)
}

Mathematical and physiological models based upon observations made after administration of a dose of radioactive iodide have been used to describe thyroid function. A troublesome feature of these models has been the "volume of distribution" of radioiodide, that is, the volume occupied by nonthyroidal, nonurinary radioiodide if its concentration throughout the compartment equals that in plasma. In most such models (1-8) this volume of distribution is assumed to be constant after an initial brief period of expansion due to diffusion of radioiodide into interstitial and intracellular fluids. As a corollary to this assumption, the logarithm of the concentration of radioactivity in plasma should be a linear function of time. It has been noted frequently that actual observations made in the first few hours after radioiodide administration fail to conform to these assumptions. Some workers have chosen to begin their analyses several hours after radioiodide administration to avoid this problem $(1,9)$. Others $(10-12)$ have measured the early volume of distribution empirically and used these observations for clinical and research purposes without analyzing why the volume of distribution is slow to reach a constant value.

Riggs (1) suggested that concentration of iodide in the salivary and gastric secretions may account for a large part of the volume of iodide distribution, but he did not expand on this suggestion. The study to be presented in this paper is an assessment of the actual importance of the gastrointestinal radioiodide compartment and its relation to the other iodide compartments of the body. For this purpose, frequent measurements were made of radioactivity present in the thyroid, urine, plasma, and gastrointestinal pool for 3 hours

\footnotetext{
* Submitted for publication June 19, 1964 ; accepted September 24, 1964.

$\dagger$ U. S. Public Health Service postdoctoral fellow in endocrinology.
}

after $\mathrm{I}^{131}$ injection. The apparent expansion of the volume of distribution is delimited and explained. A mathematical model derived from the data is presented in another paper (13).

\section{Methods}

Nine male college students, paid volunteers, were studied, each in two separate sessions, 2 weeks or more apart. All were in apparent good health and had normal thyroid function by history, physical examination, and serum protein-bound iodine.

In both sessions, a plastic nasogastric tube was passed into the stomach and kept in place throughout the experimental period. In one session, which will be referred to as the "aspiration" session, gastric contents were aspirated continuously and collected in 5-minute pools. (No attempt was made to collect saliva separately. All references to gastric contents therefore refer to pooled saliva and gastric juice.) In the alternate session, the "control" session, no gastric contents were removed, although the tube was manipulated from time to time to assure its placement in the stomach. For five subjects, the first session was a control session; for four, it was an aspiration session. In all respects except the removal of gastric contents, the two sessions were identical.

After placement of the nasogastric tube, the subject reclined on a stretcher where he remained throughout the experiment except for standing when asked to urinate. After control measurements had been made, approximately $30 \mu \mathrm{c}$ of carrier-free $\mathrm{I}^{131}$ in $5 \mathrm{ml}$ of normal saline was injected intravenously into the forearm opposite that used for blood sampling. Counts were made over the thyroid $1,2,3,4,5,7$, and 10 minutes after the $I^{132}$ injection and every 5 minutes thereafter. Blood samples $(3 \mathrm{ml})$ were drawn through an indwelling polyethylene catheter at $2,3,4,5,7$, and 10 minutes and subsequently every 5 minutes. Urine samples were collected at 15 minutes, 30 minutes, and subsequently every 30 minutes. Counts were made over the thigh at 10 minutes, 25 minutes, and at 15-minute intervals thereafter. Measurements were terminated after 180 minutes.

Heparinized plasma and samples of urine and of gastric contents (liquified with sodium hydroxide if necessitated by thick mucus) were counted in a well-type scintillation counter. These counts were related to simultaneous counts of a sample of the administered $I^{131}$ solu- 
tion, and the results were expressed as per cent of the administered dose of radioactivity present.

Counts of radioactivity over the neck and the thigh were made with a movable scintillation counter with crystal distance $13 \mathrm{~cm}$ from the skin. Care was taken to duplicate the placement of the probe for successive counts. A standard for these counts consisted of $1 \mathrm{ml}$ of $\mathrm{I}^{181}$ from the bottle that supplied the dose, placed in a $50-\mathrm{ml}$ beaker and diluted to $25 \mathrm{ml}$ with water. This standard was counted with the beaker placed on the stretcher, its top at the same position relative to the probe as that of the subject's skin. This standard was made up and counted in duplicate. All neck and thigh counts were expressed in terms of the per cent of the administered radioactivity present. "Thyroidal" radioactivity was obtained by correction of the neck counts for extrathyroidal radioactivity, utilizing plasma counts in the correction. ${ }^{1}$

1 For the correction of the thyroid counts for radioactivity from extrathyroidal structures seen by the neck probe, all radioactivity seen by the probe 2 minutes after injection of the isotope was assumed to be extrathyroidal. Two minutes was chosen as the earliest feasible time for this measurement because we have noted that earlier neck counts are erratic. As this radioactivity is primarily due to the large vessels in the neck or to tissues that rapidly diffuse iodide, it is presumed to be proportional to the plasma radioiodide level at any time early after $\mathrm{I}^{131}$ injection. If $\mathrm{N}_{2}$ and $\mathrm{N}_{t}$ represent neck counts at times 2 minutes and $t$ minutes, respectively, $\mathrm{E}_{2}$ and $E_{t}$ are the corresponding extrathyroidal neck radioactivity, $\mathrm{P}_{2}$ and $\mathrm{P}_{t}$ are the corresponding plasma counts,

TABLE I

Observed distribution of radioactive iodine: mean values for nine subjects (per cent of administered dose)

\begin{tabular}{|c|c|c|c|c|c|c|c|}
\hline \multirow{3}{*}{ Time } & \multicolumn{4}{|c|}{ Aspiration session } & \multirow{2}{*}{\multicolumn{3}{|c|}{ Control session }} \\
\hline & \multirow[b]{2}{*}{$\begin{array}{c}\text { Cumulative } \\
\text { thyroidal } \\
\text { uptake* }\end{array}$} & \multirow[b]{2}{*}{$\underset{I^{131}}{\text { Plasma }}$} & \multicolumn{2}{|c|}{ Increment } & & & \\
\hline & & & Urine & $\overline{\substack{\text { Gastric } \\
\text { juice }}}$ & $\begin{array}{c}\text { Cumulative } \\
\text { thyroidal } \\
\text { uptake* }\end{array}$ & $\underset{I^{131}}{\text { Plasma }}$ & $\begin{array}{l}\text { Increment } \\
\text { in urine }\end{array}$ \\
\hline $\min$ & $\%$ & $\% / L$ & $\%$ & $\%$ & $\%$ & $\% / L$ & $\%$ \\
\hline 2 & 0.00 & & & & 0.00 & & \\
\hline 5 & 2.17 & 6.21 & & 0.48 & 1.50 & 6.78 & $\therefore$ \\
\hline 10 & 3.55 & 5.38 & & 0.49 & 2.88 & 5.84 & \\
\hline 15 & 3.56 & 5.40 & $5.05 t$ & 0.60 & 3.87 & 5.39 & $4.13 \dagger$ \\
\hline 20 & 4.07 & 5.02 & & 0.73 & 4.31 & 5.00 & \\
\hline 25 & 4.80 & 4.72 & & 0.61 & 4.83 & 4.66 & \\
\hline 30 & 5.21 & 4.51 & $3.48 \dagger$ & 0.73 & 5.39 & 4.42 & $2.98 \dagger$ \\
\hline 35 & 5.49 & 4.29 & & 0.75 & 5.76 & 4.24 & \\
\hline 40 & 5.86 & 4.14 & & 0.65 & 6.26 & 4.06 & \\
\hline 45 & 6.39 & 3.97 & & 0.76 & 6.54 & 3.99 & \\
\hline 50 & 6.46 & 3.81 & & 0.90 & 6.92 & 3.87 & \\
\hline 55 & 6.84 & 3.71 & & 1.19 & 7.23 & 3.75 & \\
\hline 60 & 7.12 & 3.60 & $4.75 t$ & 0.94 & 7.70 & 3.66 & $4.33 t$ \\
\hline 65 & 7.50 & 3.42 & & 0.59 & 8.05 & 3.47 & \\
\hline 70 & 7.45 & 3.34 & & 0.83 & 8.25 & 3.38 & \\
\hline 75 & 7.87 & 3.28 & & 0.54 & 8.52 & 3.35 & \\
\hline 80 & 8.08 & 3.17 & & 0.53 & 8.66 & 3.30 & \\
\hline 85 & 8.12 & 3.04 & & 0.69 & 8.89 & 3.28 & \\
\hline 90 & 8.54 & 2.94 & $3.58 \pm$ & 0.62 & 9.24 & 3.20 & $3.66 t$ \\
\hline 95 & 8.59 & 2.92 & & 0.45 & 9.27 & 3.19 & \\
\hline 100 & 8.87 & 2.88 & & 0.79 & 9.75 & 3.06 & \\
\hline 105 & 8.93 & 2.84 & & 0.59 & 10.0 & 3.01 & \\
\hline 110 & 9.21 & 2.72 & & 0.74 & 10.4 & 2.93 & \\
\hline 115 & 9.40 & 2.68 & & 1.07 & 10.4 & 2.92 & \\
\hline 120 & 9.68 & 2.66 & $3.13 f$ & 0.65 & 10.9 & 2.89 & $3.34 t$ \\
\hline 125 & 9.86 & 2.60 & & 0.39 & 10.9 & 2.89 & \\
\hline 130 & 10.0 & 2.53 & & 0.56 & 11.0 & 2.87 & \\
\hline 135 & 10.4 & 2.46 & & 0.44 & 11.3 & 2.81 & \\
\hline 140 & 10.3 & 2.44 & & 1.00 & 11.5 & 2.73 & \\
\hline 145 & 10.7 & 2.32 & & 0.49 & 11.8 & 2.75 & \\
\hline 150 & 10.9 & 2.31 & $2.84 t$ & 0.44 & 12.3 & 2.69 & $3.08 \ddagger$ \\
\hline 155 & 10.8 & 2.27 & & 0.34 & 12.2 & 2.67 & \\
\hline 160 & 11.3 & 2.21 & & 0.45 & 12.5 & 2.68 & \\
\hline 165 & 11.1 & 2.15 & & 0.45 & 12.5 & 2.66 & \\
\hline 170 & 11.2 & 2.16 & & 0.33 & 12.9 & 2.64 & \\
\hline 175 & 11.4 & 2.08 & & 0.56 & 13.3 & 2.60 & \\
\hline 180 & 11.8 & 2.06 & $2.25 t$ & 0.60 & 13.3 & 2.59 & $2.99 \ddagger$ \\
\hline
\end{tabular}

* After correction for neck background, assuming $\mathrm{P}_{2}=\mathbf{8 . 0 0}$.

+15 -minute collection.

$\ddagger 30$-minute collection. 


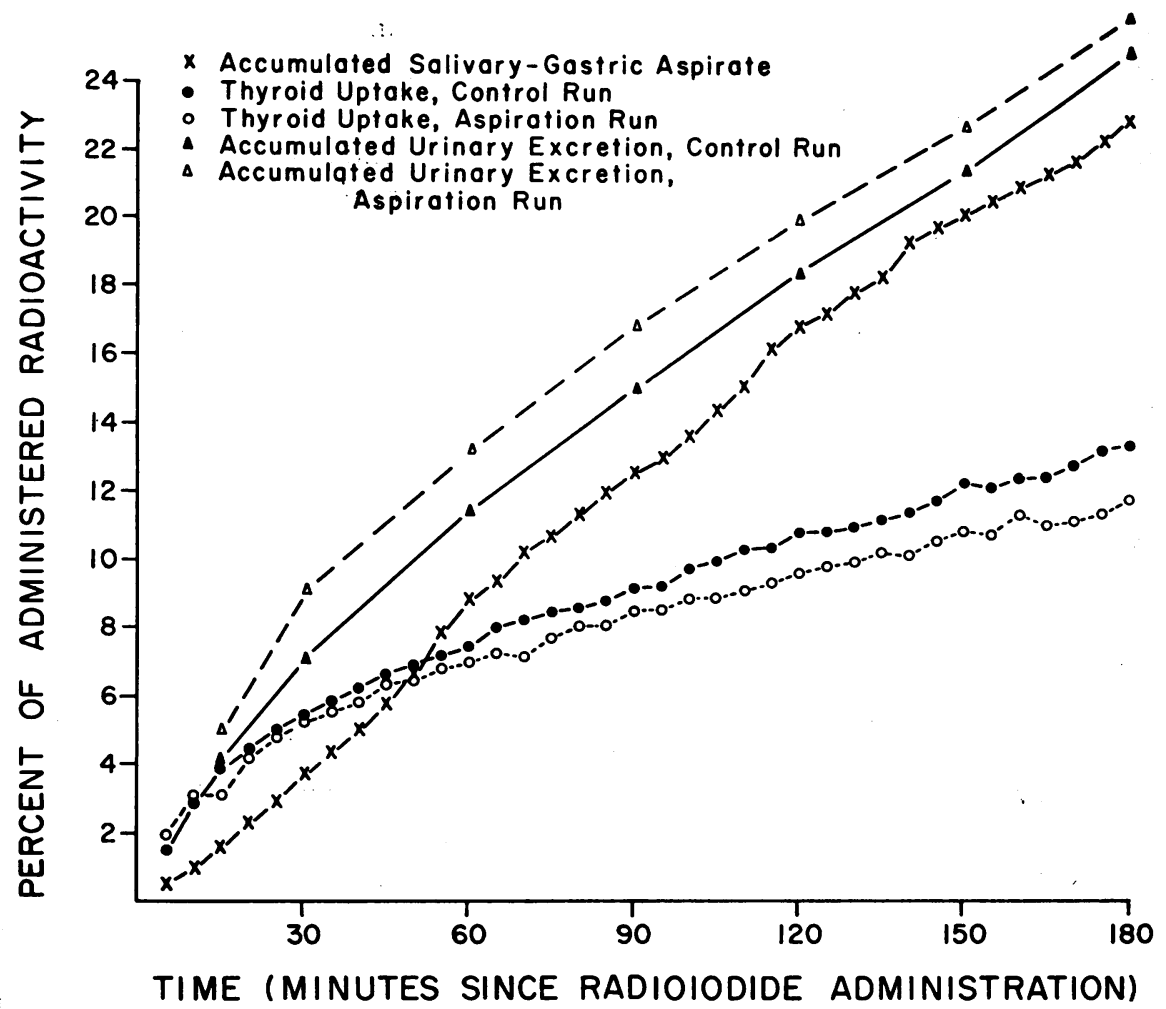

Fig. 1. Cumulative thyroidal, URINARY, AND GaStrosalivary Radioactivity.

\section{Results}

The data averaged for the nine subjects are presented in Table $\mathrm{I}$. The range of the 3-hour values for the individual subjects was as follows in the aspiration session: cumulative gastric aspirate, 11.2 to $43.9 \%$; thyroidal uptake, 6.90 to $25.1 \%$; cumulative urinary excretion, 19.0 to $34.6 \%$; and plasma radioiodide per liter, 1.54 to $2.46 \%$. In the control session, ranges were as follows: thyroidal uptake, 9.45 to 23.0 ; cumulative urinary excretion, 19.5 to 30.7 ; plasma, 2.18 to 2.97 . The coefficient of variation for each time point was determined as an estimate of variation from sub-

and $T_{t}$ is actual thyroidal radioactivity, the following relations hold: 1) $\mathrm{N}_{2}=\mathrm{E}_{2}$, 2) $\mathrm{E}_{2} / \mathrm{P}_{2}=\mathrm{E}_{\mathrm{t}} / \mathrm{P}_{\mathrm{t}}$, 3) $\mathrm{N}_{2} / \mathrm{P}_{2}$ $\left.=E_{t} / P_{t}, 4\right) T_{t}=N_{t}-E_{t}$, and 5) $T_{t}=N_{t}-P_{t}\left(N_{2} / P_{2}\right)$.

Because of the difficulties in obtaining the 2-minute plasma sample, it of ten proved unreliable, and in a number of : subjects $P_{2}$ had to be established by extrapolation from the earliest smooth portion of the plasma curve. For calculations made from the pooled data of all subjects, $\mathrm{P}_{2}$ was assumed from extrapolation to be $8 \%$ of the dose per $\mathrm{L}$ of plasma. These extrapolated values admittedly are subject to error, but the over-all effect of this error on the analysis is small. ject to subject. The mean coefficient of variation was $12.3 \%$ for plasma, $19.1 \%$ for urine, $22.5 \%$ for thyroid, and $78.1 \%$ for gastric aspirate. The large coefficient of variation for the gastric aspirate reflects both a wide variability between subjects and an irregularity in the rate of removal through the stomach tube.

Figure 1 shows the averaged cumulative data for the thyroidal, urinary, and gastric radioiodide. Thyroidal uptake during the control session followed the pattern frequently observed in past work, in which radioactivity rises rapidly initially and the rate of rise then gradually decreases. The uptake curve flattened more rapidly in the aspiration than in the control situation, largely due to the more rapid fall in plasma radioactivity. The thyroidal clearance in milliliters per minute was calculated as

$1 / 5$ (increment in thyroidal $\mathrm{I}^{131}$ during 5 minutes) $1 / 1,000$ (corresponding plasma $\mathrm{I}^{\mathbf{1 3 1}}$ )

This value, although it varied widely from measurement to measurement owing to variability in the neck counts, did not vary significantly with time in either the aspiration or the control ses- 
sion. The average value for thyroidal clearance was $16 \mathrm{ml}$ per minute $(15 \mathrm{ml}$ per minute in the aspiration session and $17 \mathrm{ml}$ per minute in the control session).

The cumulative urinary excretion of radioiodide rises in a pattern similar to that of thyroidal uptake. Renal clearance, calculated in the same manner as for the thyroid but allowing for a 10 minute lag between removal from the plasma and voiding, ${ }^{2}$ averaged $34 \mathrm{ml}$ per minute $(36 \mathrm{ml}$ per minute in the aspiration session and $32 \mathrm{ml}$ per minute in the control session). Although the difference between these clearances is not statistically significant, the higher average renal clearance in the aspiration session accounts for the slightly higher urine curve in Figure 1.

The curve for the accumulated gastric aspirate is complex (Figure 1), unlike the pattern seen for thyroidal and urinary radioiodide accumulation. By direct measurement, clearance of plasma radioiodide by gastric juice was initially low, rising to $46 \mathrm{ml}$ per minute for the averaged data at about 45 minutes. Individual gastrosalivary clearances ranged from 24 to $104 \mathrm{ml}$ per minute.

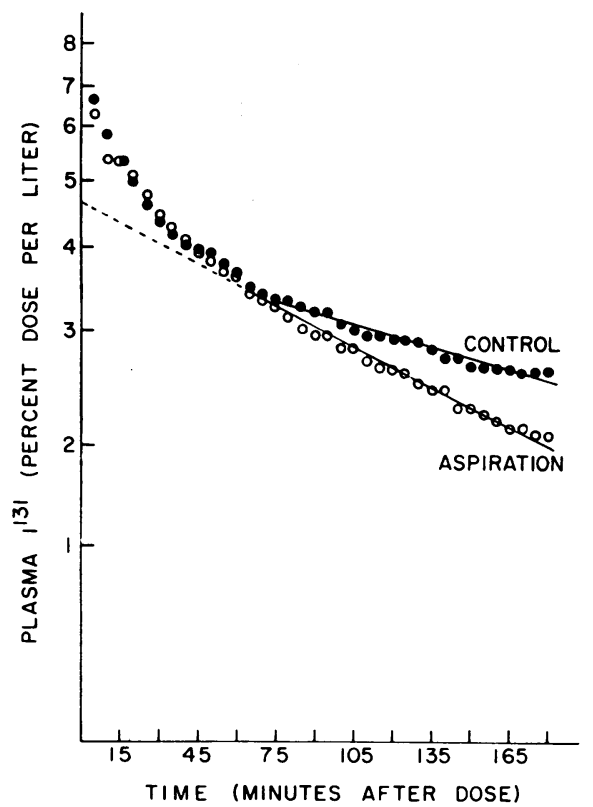

Fig. 2. Plasma radioactivity (averaged data).

2 The figure of 10 minutes for the lag between removal of radioiodide from the plasma and its appearance in the voided urine was arrived at by statistical analysis of clearance values calculated from various lag periods. It is in keeping with considerations discussed by Smith (14).
Under unchanging conditions of gastric and salivary blood flow, one would expect clearance of radioiodide from the plasma by the stomach and salivary glands to be constant. Therefore, the delayed appearance of radioactivity in the gastric aspirate suggests significant retention of cleared radioiodide in the gastric glands and folds. Because of this retention, true clearance values should have been calculated with earlier, higher plasma radioactivity levels in the denominator and would have been lower than $46 \mathrm{ml}$ per minute. This delay was measured and corrected for by application of a mathematical model (13). For the averaged data, the delay between removal of radioiodide from the plasma and its appearance in the gastric aspirate was found to be 22 minutes. The clearance rate calculated from this model was $40 \mathrm{ml}$ per minute.

Figure 2 shows the average plasma $\mathrm{I}^{131}$ levels for the two experimental sessions (on a log scale) plotted against time. Early in both sessions, the plasma levels fell rapidly. This fall presumably corresponded to rapid equilibration with the erythrocytes and with the interstitial fluid. There was then a slower fall before the linear phase was reached after approximately 1 hour. This slower fall corresponded to distribution into what we shall refer to as the "slowly diffusible space." This space probably consists of certain intracellular areas and poorly accessible extracellular compartments.

In the aspiration session, in which intestinal reabsorption of the radioiodide cleared by the salivary glands and stomach was circumvented, plasma radioactivity showed a constant logarithmic fall during the latter parts of the experiment. This reflected a constant rate of essentially irreversible removal of radioiodide by the thyroid, the kidney, and the gastrointestinal tract. That this was the case and that no other sites of removal were important are proved by the following calculation.

The straight logarithmic portion of the mean pooled aspiration session plasma curve best fits the following equation: $\log _{10}$ (plasma $I^{131}$ ) = $0.671-0.00206$ (time in minutes). The intercept, 0.671 , is the $\log _{10}$ of $4.69 \%$ per L. $100 \%$ / $4.69 \%$ per $\mathrm{L}=21.33 \mathrm{~L}$, an approximation of the volume of radioiodide distribution. However, because of disproportionate loss of radioiodide 

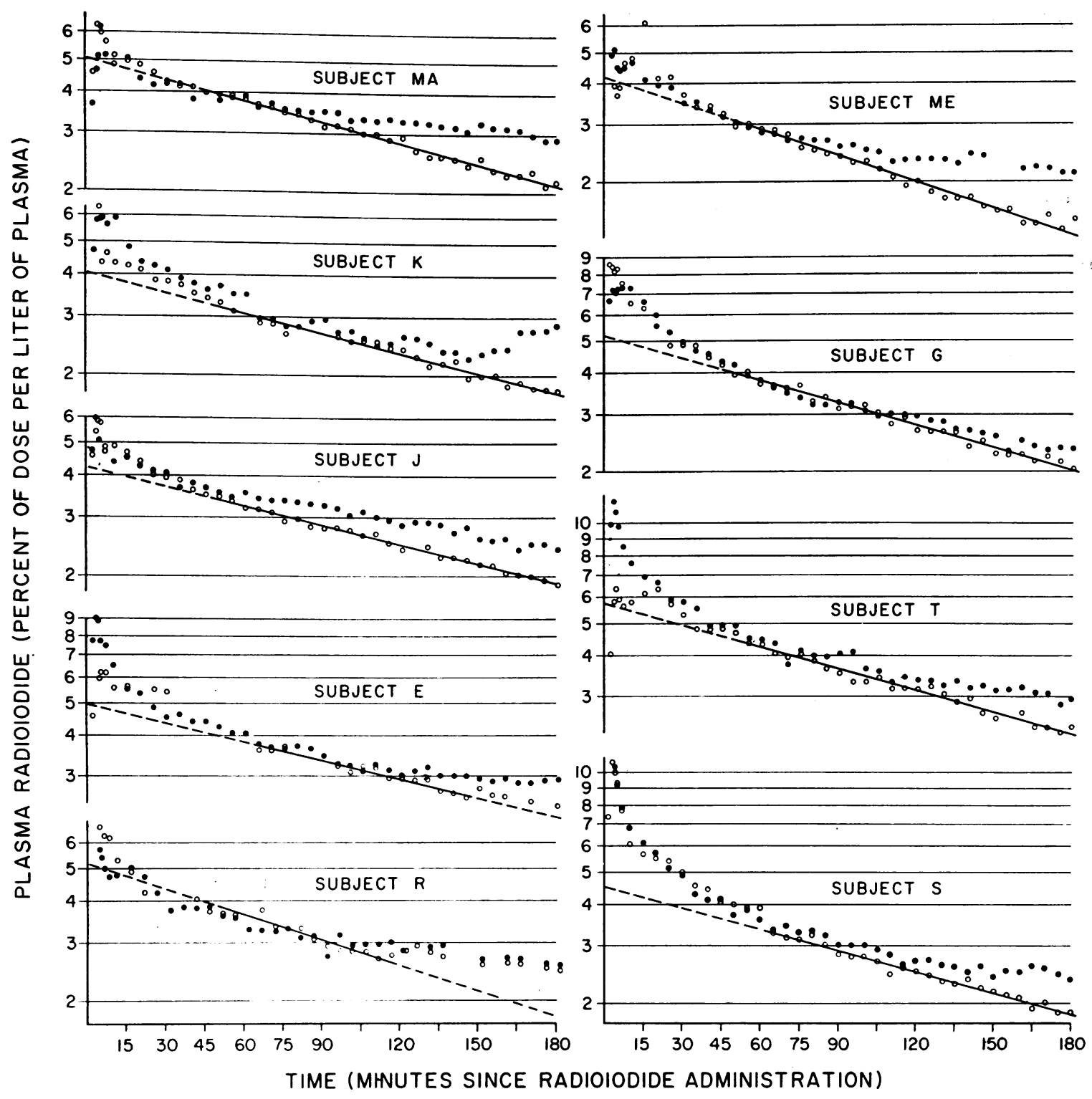

- Control Session - Aspiration Session

Fig. 3. Plasma radioactivity in individual subjects.

during the early nonlinear phase of the curve, the linear portion of the curve is lower than would have been seen in the case of instantaneous equilibration. Hence, the above estimate of volume of distribution is somewhat high. We shall accept the value of $20.0 \mathrm{~L}$, arrived at by direct measurement (see below). The slope, converted to base $e$, is $-0.00206 / 0.4343=-0.00473$. With a volume of distribution of $20.0 \mathrm{~L}$, the total irreversible clearance is $(0.004743)(20,000)=95 \mathrm{ml}$ per minute. Direct measurement has established thy- roidal and renal clearances to be $16 \mathrm{ml}$ per minute and $36 \mathrm{ml}$ per minute. The gastrosalivary clearance, when corrected for delay due to retention in the inaccessible gastric space, is $40 \mathrm{ml}$ per minute. [Calculation of this space is shown fully in the mathematical analysis of these data (13).] The three known sites of essentially irreversible clearance, then, account for $92 \mathrm{ml}$ per minute, which closely approximates the value calculated from the slope of the log plasma curve.

In the control session, the log plasma curve ini- 
tially followed the same pattern as that seen in the aspiration session. At about 45 minutes, however, it rose questionably in relation to the aspiration session, and at 75 minutes the two curves definitely diverged. As the only difference between the two sessions was circumvention of intestinal reabsorption in the aspiration session, this relative rise in plasma radioactivity in the control session was presumably due to intestinal reabsorption of previously cleared radioiodide and its reintroduction into the circulation.

Although the log plasma radioiodide concentration curve for the control session did not become truly linear, it is possible to calculate a reasonable regression line with the data from 90 through 180 minutes : $\log _{10}$ plasma $=0.606-0.001137$ (time in minutes). Calculation of the net "irreversible" distribution of plasma represented by this slope is then possible: $(-0.001137 / 0.4343) \times 20,000=$ $-52 \mathrm{ml}$ per minute. This figure coincides with the observed sum of the thyroidal and renal clearances. The difference between it and the comparable value in the aspiration session $(95-52=43$ $\mathrm{ml}$ per minute) is an estimate in terms of current plasma radioactivity of the rate of reappearance of gastrointestinal radioiodide in the plasma. This estimate compares well with the directly observed gastrosalivary clearance rate. As was the case with the gastrosalivary clearance rate, this figure should be corrected for the drop in plasma radioactivity during the interval radioiodide has remained in the gastrointestinal tract. Calculations based on the mathematical model (13) set the average for this time lag at $57 \mathrm{~min}$ utes. When corrected for the drop in plasma radioactivity during this interval, the "reverse clearance" becomes $37 \mathrm{ml}$ per minute. This figure compares well with the $40 \mathrm{ml}$ per minute "corrected" value for gastrosalivary clearance rate.

Figure 3 shows the individual pair of plasma curves for each of the nine subjects. Except for Subject $R$, in whose case gastric suction was apparently incomplete, the individual plasma values from the aspiration session fell logarithmically with time after 1 hour, as was seen in the averaged data. There was, however, wide variation in the
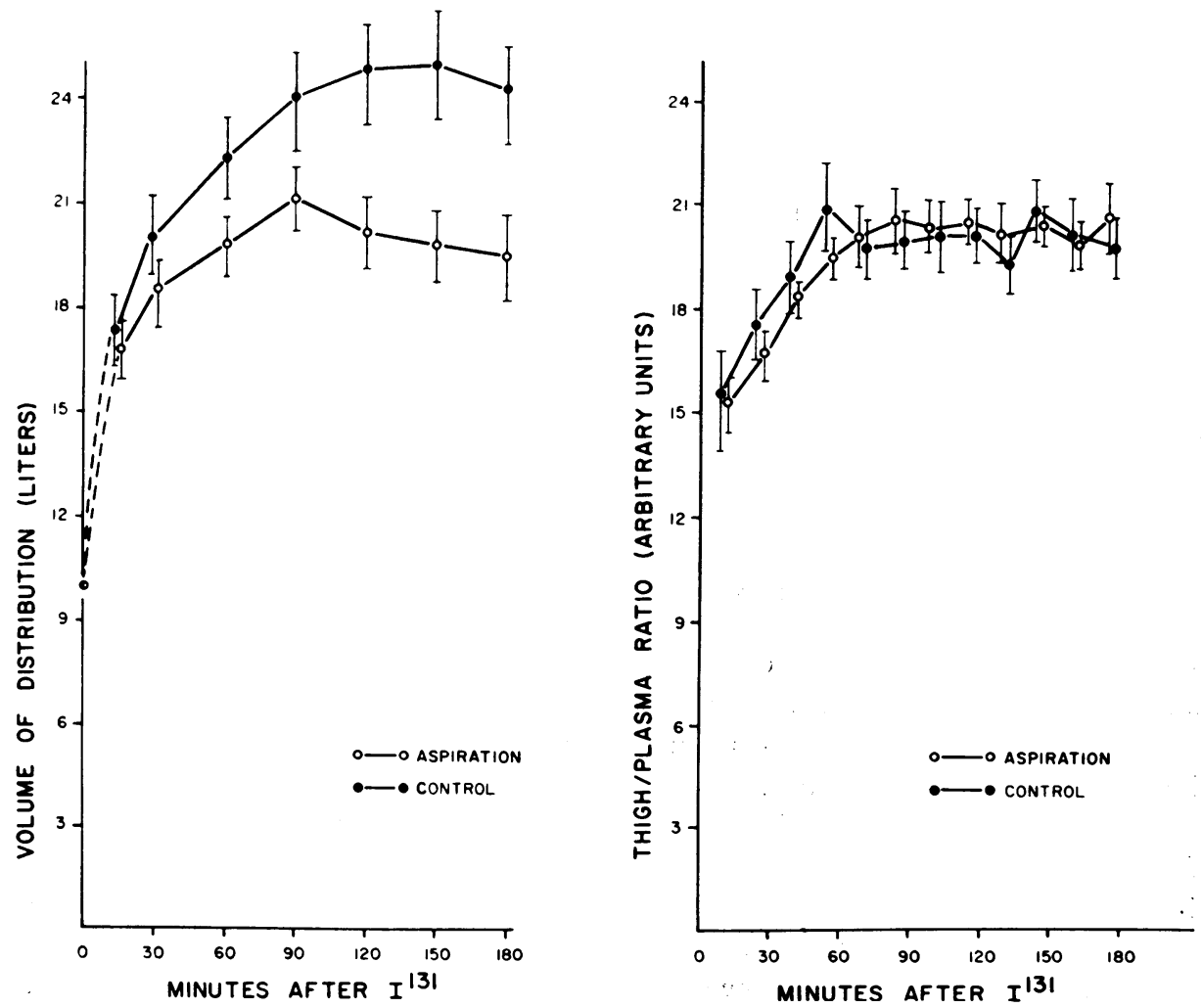

Fig. 4. Volume of distribution calculated by the balance Method (LEFT) AND ESTimated FROM THE THIGH/PLASMA RATIO (RIGHT). 


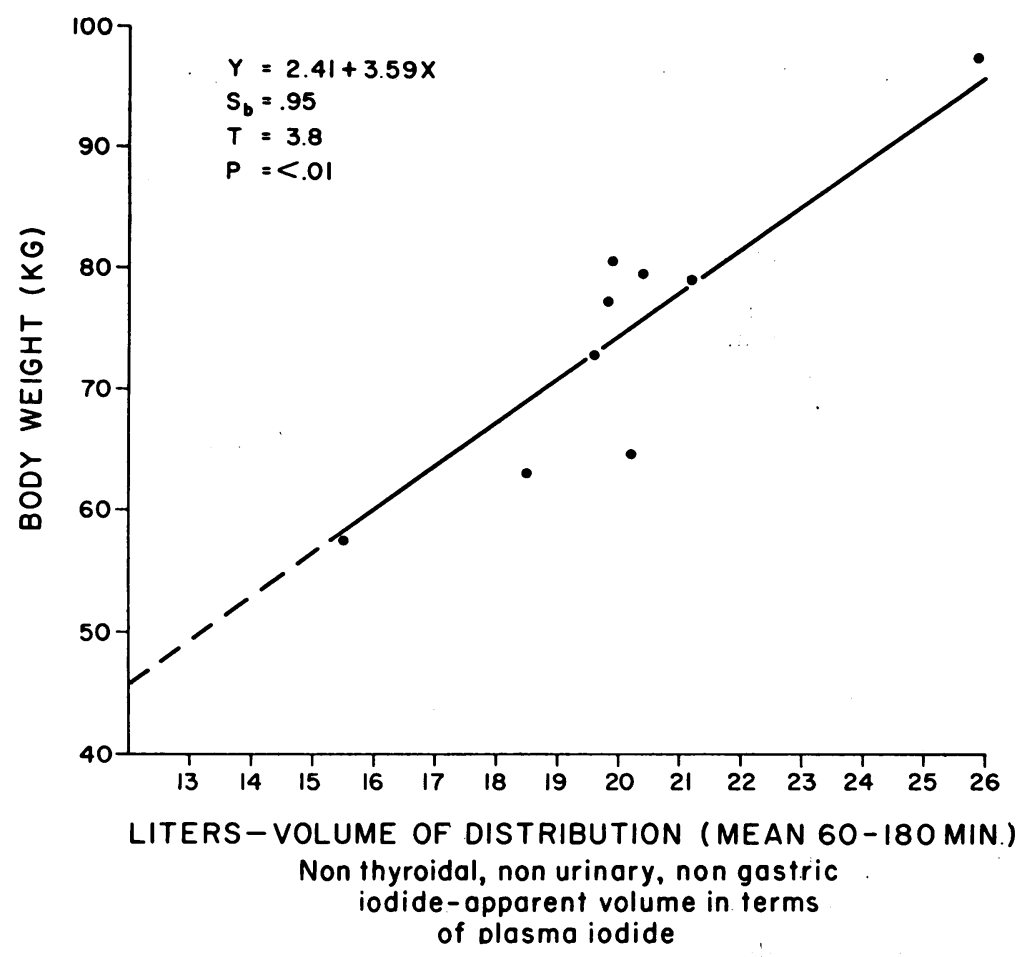

Fig. 5. Correlation of volume of Distribution and body Weight.

timing, degree, and shape of the rise of the control curve over the aspiration curve. Analysis of these curves using the model derived from the averaged data is presented elsewhere (13).

When all of the $I^{131}$ dose that cannot be accounted for by thyroidal uptake and urinary excretion is divided by the amount present in $1 \mathrm{~L}$ of plasma, the result is a second estimate of the "volume of distribution" (V). This is the sum of the sizes of the various compartments of radioiodide distribution, when each has been corrected for its concentration of radioiodide relative to that of plasma. In the control session of this experiment, $\mathrm{V}$ was calculated in the usual manner. In the aspiration session, the radioiodide removed from the stomach was also subtracted in determining the radioactivity left in the volume of distribution. The difference between these two calculations was a rough estimate of the gastrointestinal volume of distribution. The left half of Figure 4 shows the averaged figures for these two calculations, with indication of the standard error of the mean. Because each calculation of volume of distribution combined three or four data, each of which was subject to observational and random error, the resulting figure manifested an even greater error. Nevertheless, the averaged values were essentially constant at $20 \mathrm{~L}$ from 60 minutes to the end of the aspiration session. This constant level is taken as the equilibrium nonthyroidal, nonurinary, nongastrointestinal volume of distribution. This level for the individual subjects was found to correlate well with body weight (Figure 5). The calculated line of best fit can be used for predicting : $V$ at equilibrium: $V=$ (body weight in kilograms -2.41 )/3.59. If one assumes zero intercept; the slope is not changed significantly. One then obtains a simpler formula: $\mathrm{V}=$ 0.27 (body weight in kilograms).

An indirect measure of the tissue volume of distribution that has been used in the past is the thigh/plasma ratio (10). In both sessions of this experiment, the curves showing the averaged data for this ratio correspond well with the curve for the volume of distribution in the aspiration session (Figure 4, right half). This confirms the assumption that the volume measured is actually extracellular and tissue space, with no other large volumes (such as the gastrointestinal) unaccounted for. On the individual basis, however, the thigh/ plasma ratio was not so good a predictor of radioiodide space as was body weight (Table II). 
TABLE II

Statistics for regression of volume of distribution against body weight and against thigh/plasma ratio

\begin{tabular}{|c|c|c|}
\hline $\mathrm{X}$ & Body weight & $\begin{array}{l}\text { Thigh/plasma ratio } \\
(70-175 \text { minute mean, both } \\
\text { sessions })\end{array}$ \\
\hline$Y$ & $\begin{array}{l}\text { Volume of distribution } \\
\text { (nonthyroidal, nonurinary, } \\
\text { nongastrointestinal } 60-180 \text { minute } \\
\text { mean) }\end{array}$ & $\begin{array}{l}\text { Volume of distribution } \\
\text { (same) }\end{array}$ \\
\hline Regression equation & $Y=2.41+3.59 X$ & $Y=0.331+0.014 X$ \\
\hline $\mathrm{S}_{\mathrm{b}} *$ & 0.95 & 0.0073 \\
\hline$\frac{\mathrm{b}}{\mathrm{S}_{\mathrm{b}}}=t$ & 3.8 & 1.78 \\
\hline $\mathrm{p}$ & $<0.01$ & $<0.20$ \\
\hline
\end{tabular}

* Standard error of slope.

Eight of the nine individual curves of volume of distribution during the aspiration session followed the pattern of the averaged data. The ninth subject showed continued increase in the volume of distribution as calculated, but his curve of thigh/ plasma ratio was stable after 60 minutes. Mathematical analysis of this subject's data (13) suggests that aspiration of gastric contents was complete but that some of the radioactivity removed escaped measurement. An increase in $\mathrm{V}$ would result from this error, as the denominator of the ratio (plasma radioactivity) would decrease as expected, but the numerator (radioactivity remaining in V) would not decrease as rapidly as it should.

Figure 4 shows that, on the average, the total volume of radioiodide distribution in the control session became essentially constant after 90 or 120 minutes in this experiment. However, there was wide individual variation, presumably due to

TABLE III

Constants calculated directly from averaged data in nine subjects

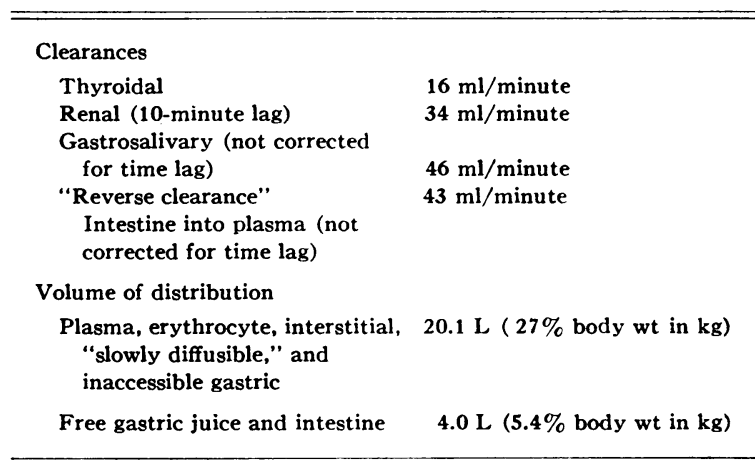

vagaries in the gastrointestinal radioiodide cycle, and in four subjects the volume of distribution appeared to increase throughout the experiment. Such individual variation probably explains the difference between the volumes of distribution found in this experiment and those of Myant, Corbett, Honour, and Pochin (10), who noted increasing volume of distribution up to 6 hours.

The difference between the "stable" portions of the curves of volume of distribution in the two experimental sessions $(24.1-20.1=4.0 \mathrm{~L})$ provides a rough estimate of the radioiodide volume contained in the free gastric juice and intestine at a given time during the control session.

Table III summarizes the estimates obtained above from the averaged data for the nine subjects.

\section{Discussion}

It has long been known that the salivary glands and gastric mucosa secrete iodide. Studies in animals (15-20) have confirmed the importance of a gastrointestinal iodide cycle in various species. Radioiodide concentration and clearance from the plasma into saliva and gastric juice have been measured in man by a number of authors (Table IV, references 21-27). In view of the wide range of individual variation, there is probably no significant difference between the clearance reported here and those reported by others.

As fecal iodide excretion is negligible in man, it seems justifiable to assume that all of the secreted radioiodide is sooner or later reabsorbed by the small or large intestine. In fact, the process is probably complex. Iodide secretion is known 
TABLE IV

Published estimates of gastrosalivary iodide concentration ratios and clearance

\begin{tabular}{|c|c|c|c|c|c|}
\hline \multirow[b]{2}{*}{ Author, reference } & \multicolumn{2}{|c|}{$\begin{array}{l}\text { Concentration ratio } \\
\text { over plasma }\end{array}$} & \multicolumn{3}{|c|}{ Clearance } \\
\hline & Saliva (S/P) & Gastric (G/P) & Salivary & Gastric & Combined \\
\hline & & & \multicolumn{3}{|c|}{ ml/minute } \\
\hline \multirow{6}{*}{$\begin{array}{l}\text { Honour, Myant, and Rowlands (21) } \\
\text { Freinkel and Ingbar (22) } \\
\text { Oeff, Krentz, and Kessel (23) } \\
\text { Gabrielsen and Kretchmar (24) } \\
\text { Fellinger, Höfer, and Vetter (25) } \\
\text { Cohen and Myant (26) } \\
\text { Schiff and associates (27) } \\
\text { Present study }\end{array}$} & 48.3 & 33.1 & \multirow{6}{*}{$\begin{array}{l}17.5 \\
46 \text { (parotid) }\end{array}$} & \multirow[t]{6}{*}{24.5} & 42 \\
\hline & 16.8 & & & & \\
\hline & 26 & 29 & & & 36 \\
\hline & & & & & \\
\hline & 24.8 & & & & \\
\hline & $29-59$ & $17-37$ & & & $46^{*}$ \\
\hline
\end{tabular}

* When corrected for change in plasma specific activity during delay in the dead space, this value is $40 \mathrm{ml}$ per minute.

to occur to some degree all along the small intestine (19) as well as in the salivary glands and stomach. Revis and Muravei have shown that all parts of the intestine are capable of radioiodine absorption (28).

Other known factors not controlled here include the slow diffusion of iodide into the cerebrospinal fluid (2) and sweat (29).

In presenting the data from this study, we have implicitly assumed that the unmeasurable factors are small and either cancel each other or are undetectable within the limits of observational error. That this assumption is justified is shown by the close approximation of the observed constants to those that can be calculated from our model reported elsewhere (13), and by the fact that the sum of the separately measured clearances (thyroid, renal, and gastrosalivary) accurately accounts for the plasma disappearance curve.

The quantitative data presented in this study confirm the importance of the gastrointestinal tract in the body's radioiodide economy. A significant portion of a dose of radioiodide, 11 to $44 \%$, with a mean of $23 \%$, was cleared by the salivary glands and gastric mucosa during the first 3 hours after intravenous injection. Pooling of radioiodide in the free gastric juice and intestine accounted, on the average, for $4 \mathrm{~L}$, or $17 \%$, of the extrathyroidal volume of radioiodide distribution. These data also show clearly that, when gastrosalivary secretions are removed by aspiration, the distribution of intravenous radioiodide is virtually complete after 1 hour. This volume of distribution was approximately $27 \%$ of body weight of these normal, nonobese subjects. When gastric contents are left in place, however, the volume of distribution continues to increase for variable periods of time, as the gastrointestinal pool slowly approaches a balance between rate of removal of radioiodide from the plasma and rate of radioiodide return through intestinal reabsorption. The delay between these processes is dependent on gastric motility, rate of pyloric emptying, and the efficiency of intestinal reabsorption. These may vary widely from subject to subject and from time to time. Gastrosalivary clearance rate also varies from subject to subject, and experimental maneuvers might alter it in an individual subject.

When intestinal reabsorption of radioiodide was prevented by aspiration of gastric contents, the log plasma curve became linear after 1 hour. In the control session, however, there was a relative upward deviation of the plasma radioiodide levels as soon as intestinal reabsorption began. The pairs of individual plasma curves (Figure 3) demonstrate the wide variations in plasma radioiodide level late in the control sessions. The factors determining the shape of this portion of the curve would again include gastric motility, pyloric emptying, and intestinal reabsorption. When passage through the pylorus is delayed for any reason, the relative rise in the control curve is delayed or reduced. "Dumping" of retained gastric juices, especially if high in specific activity, would cause a relative or even absolute rise in the control curve.

We have discussed a number of factors that might cause changes in the plasma radioiodide available for uptake by the thyroid. To detect any subtle effect of a single experimental maneuver on the thyroid by external counting, these factors 
must be controlled. To a large degree this can be done by comparison with a control experiment on the same experimental subject or patient. However, emotional factors play an important part in determining the rate of pyloric emptying and possibly in other aspects of the gastrointestinal iodide cycle. These also must be held constant for the ideal experiment. In practice, this might be possible in part by using trained subjects who have become acclimatized to the experimental setup. Alternatively, one could use an intubation technique such as described in this paper.

Often, in an experiment the real question at issue is the effect of a maneuver on the thyroid, as reflected by a change in thyroidal clearance of radioiodide. In this case, despite the technical difficulties involved, it is best to measure the clearance directly from actual blood samples drawn simultaneously with the measurement of increment in thyroidal radioactivity. The evidence presented above suggests that any short-cut measure, in which plasma radioiodide level is assumed on the basis of other data, or in which thyroidal uptake is assumed to reflect thyroidal clearance rate, is subject to significant and unpredictable error.

\section{Summary}

The salivary-gastric-enteric cycle of radioactive iodide was studied during the first 3 hours after isotope administration in nine normal subjects. Radioiodide in the thyroid, plasma, urine, and pooled salivary-gastric secretions was measured frequently. Control sessions for each subject were identical, except that no secretions were aspirated from the gastric tube. Radioiodide recovered from the stomach averaged $23 \%$ of that administered (range, 11 to $44 \%$ ). Thyroidal clearance averaged $16 \mathrm{ml}$ per minute; renal clearance, $34 \mathrm{ml}$ per minute; and gastrosalivary clearance (not corrected for dead space), $46 \mathrm{ml}$ per minute. When gastric contents were removed, the nonthyroidal, nonurinary volume of distribution remained constant (averaging $20.1 \mathrm{~L}$ or $27 \%$ of body weight) after the first hour, and plasma radioactivity declined along a simple exponential curve. The rate of this decline could be accounted for by the summed thyroidal, renal, and gastrosalivary clearance rates. In the control sessions, the increase in volume of distribution persisted longer, and in four subjects it was still evident at 180 minutes. Thigh/plasma ratio became constant after 1 hour, but was not so good a predictor of nongastrointestinal volume of distribution as was body weight. Curves of plasma radioactivity in the control sessions varied greatly among the individuals and did not follow a simple exponential function. This difference must be due to the effect of intestinal reabsorption of radioiodide previously cleared.

\section{References}

1. Riggs, D. S. Quantitative aspects of iodine metabolism in man. Pharmacol. Rev. 1952, 4, 284.

2. Myant, N. B., E. E. Pochin, and E. A. G. Goldie. The plasma iodide clearance rate of the human thyroid. Clin. Sci. 1949, 8, 109.

3. Keating, F. R., Jr., and A. Albert. The metabolism of iodine in man as disclosed with the use of radioiodine. Recent Progr. Hormone Res. 1949, 4, 429.

4. Oddie, T. H. Analysis of radio-iodine uptake and excretion curves. Brit. J. Radiol. 1949, 22, 261.

5. Berkson, J., F. R. Keating, Jr., M. H. Power, and W. M. McConahey. Determination of renal clearance of radioiodine. J. appl. Physiol. 1949, 2, 522.

6. Brownell, G. L. Analysis of techniques for the determination of thyroid function with radioiodine. J. clin. Endocr. 1951, 11, 1095.

7. Ingbar, S. H. Simultaneous measurement of the iodide-concentrating and protein-binding capacities of the normal and hyperfunctioning human thyroid gland. J. clin. Endocr. 1955, 15, 238.

8. Wollman, S. H. A thyroid model describing kinetics of exchange, concentrating, and organic binding of iodide. Endocrinology 1954, 54, 35.

9. Berman, M. Application of differential equations to the study of the thyroid system. Fourth Berkeley Symposium on Mathematical Statistics and Probability, 1961, p. 87.

10. Myant, N. B., B. D. Corbett, A. J. Honour, and E. E. Pochin. Distribution of radioiodide in man. Clin. Sci. 1950, 9, 405.

11. Oddie, T. H., I. Meschan, and J. Wortham. Thyroid function assay with radioiodine. II. Routine calculation of thyroidal and renal rate factors. J. clin. Invest. 1955, 34, 106.

12. Owen, C. A., Jr., R. S. McCants, and W. M. McConahey. Abbreviation of Berson technic for estimation of thyroidal clearance of plasma radioiodide: use of Berson test to recognize thyroidal protein-binding defects. J. clin. Invest. 1960, 39, 790.

13. Hays, M. T., and L. H. Wegner. A mathematical and physiological model for early distribution of radioiodide in man. Submitted for publication. 
14. Smith, H. W. The Kidney. New York, Oxford University Press, 1951, p. 61.

15. Davenport, H. W. The secretion of iodide by the gastric mucosa. Gastroenterology 1943, 1, 1055.

16. Mason, E. E., and H. S. Bloch. Gastric secretion of iodide at low serum iodide levels. Proc. Soc. exp. Biol. (N. Y.) 1950, 73, 488.

17. Johnson, H. W., and A. Albert. The excretion and distribution of $\mathrm{I}^{\text {13 }}$ following administration of physiologic amounts of labeled iodide, diiodotyrosine and thyroxine in the rat. Endocrinology $1951,48,669$.

18. Brown, J. Extra-thyroidal iodide metabolism in the rat. Endocrinology 1956, 58, 68.

19. Pastan, I. Absorption and secretion of iodide by the intestine of the rat. Endocrinology 1957, 61, 93.

20. Halmi, N. S., and R. G. Stuelke. Comparison of thyroidal and gastric iodide pumps in rats. Endocrinology . 1959, 64, 103.

21. Honour, A. J., N. B. Myant, and E. N. Rowlands. Secretion of radioiodine in digestive juices and milk in man. Clin. Sci. 1952, 11, 447.

22. Freinkel, $N_{\text {, }}$ and $S$. H. Ingbar. Concentration gradients for inorganic $\mathrm{I}^{121}$ and chloride in mixed human saliva. J. clin. Invest. 1953, 32, 1077.
23. Oeff, K., K. Krentz, and M. Kessel. J-131 Clearance der normalen und pathologischen Magenschleimhaut. Klin. Wschr. 1955, 33, 59.

24. Gabrielsen, Z., and A. L. Kretchmar. Studies on the salivary secretion of iodide. J. clin. Endocr. 1956, 16, 1347.

25. Fellinger, K., R. Höfer, and H. Vetter. Salivary and thyroidal radioiodide clearances of plasma in various states of thyroid function. J. clin. Endocr. 1956, 16, 449.

26. Cohen, B., and N. B. Myant. Concentration of salivary iodine. A comparative study. J. Physiol. (Lond.) 1959, 145, 595.

27. Schiff, L., C. D. Stevens, W. E. Molle, H. Steinberg, C. W. Kumpe, and P. Stewart. Gastric (and salivary) excretion of radioiodine in man. J. nat. Cancer Inst. 1947, 7, 349.

28. Revis, V. A., and I. P. Muravei. Absorption of radioiodine by various portions of the gastrointestinal tract. Klin. Med. (Mosk.) 1959, 37 (no. 4), p. 51 .

29. Nelson, N., E. D. Palmes, C. R. Park, P. P. Weymouth, and W. B. Bean. The absorption, excretion, and physiological effect of iodine in normal human subjects. J. clin. Invest. 1947, 26, 301. 